\title{
A wearable antenna based on fabric materials with circular polarization for body-centric wireless communications
}

\author{
Adel Y. I. Ashyap", Z. Z. Abidin', Samsul Haimi Dahlan", Shaharil Mohd Shah ${ }^{4}$, Huda A. Majid", \\ Yee See Khee $^{6}$, Norun Abdul Malek ${ }^{7}$ \\ 1,2,3,4,5,6 Research Center of Applied Electromagnetics, Faculty of Electrical and Electronic Engineering, \\ Universiti Tun Hussein Onn Malaysia (UTHM), Malaysia \\ ${ }^{7}$ International Islamic University Malaysia, Malaysia
}

\begin{tabular}{l}
\hline \hline Article Info \\
\hline Article history: \\
Received Aug 29, 2019 \\
Revised Oct 8, 2019 \\
Accepted Nov 6, 2019 \\
\hline
\end{tabular}

\section{Keywords:}

Axial Ratio

Circular polarization

ISM band

SAR

Wearable antenna

\begin{abstract}
A compact and simple structure antenna for wearable application at $2.4 \mathrm{GHz}$ is presented and studied. The felt fabric material is used in this paper due to its suitable thickness and dielectric constant. This material provides high flexibility which can be easily worn on a body and incorporated into our daily clothes. In view of the fact that the design will work on a moving person, therefore a circularly polarized antenna is desired to optimize the offbody communication link. The Cicular Polarization (CP) is achieved by introducing truncated corners on the patch. The antenna size is $60 \times 60 \times 2$ mm3. The Axial Ratio (AR), the Front to Back Ratio (FRB) and the realized gain are $0.96 \mathrm{~dB}, 10.5 \mathrm{~dB}$, and $4.62 \mathrm{~dB}$, respectively indicating a good performance of the antenna at the desired frequency. Furthermore, the antenna was investigated when operating near the body. The obtained result shows that the design has performance similar to the case of free space. This is due to the present of the full ground plane that acts as a shielding between the antenna and body. Finally, the Specific Absorption Rate (SAR) is carried out and showed that the antenna has a level less than the limits fixed by the FCC standard. Therefore, the antenna could be useful for wearable applications.
\end{abstract}

Copyright $@ 2020$ Institute of Advanced Engineering and Science. All rights reserved.

\section{Corresponding Author:}

Zuhairiah Zainal Abidin, Research Center of Applied Electromagnetics, Institute for Integrated Engineering $\left(\mathrm{I}^{2} \mathrm{E}\right)$,

Universiti Tun Hussein Onn Malaysia (UTHM),

Batu Pahat, Johor, Malaysia.

Email: zuhairia@uthm.edu.my

\section{INTRODUCTION}

The development of portable wireless communication systems prompted researchers to focus on the design of small-sized antennas. The most valuable among the small-sized antenna selections is the microstrip patch antenna. These antennas are characterized by important features such as compact, low cost, lightweight polarization diversity, and low profile. The wearable antennas, which are part of our daily clothes, are utilized for communication purposes such as health monitoring, sports, tracking, military, public safety, firefighters and mobile computing. Besides that, a wearable antenna considers one of the most vital parts of wearable electronic devices [1-9].

Wearable antennas are employed as transmitter and receiver nodes in Wireless Body Area Network (WBAN) devices for the purpose of sending and receiving the information or data. These antennas are maintained flexible therefore they don't prevent the movement of the body. To ensure the flexibility of these antennas, various flexible materials are utilized as essential parts for the design of wearable antennas [10-15]. 
Due to the continuous movement of human body, it is relatively difficult to obtain the appropriate polarization alignment to maintain an acceptable power received by the transceiver $[15,16]$. Therefore, a circular polarization $(\mathrm{CP})$ is introduced to overcome the misalignment by aligning two nodes continuously to receive maximum power. In that case, a wearable antenna with circular polarization $(\mathrm{CP})$ has the advantages in terms of mobility and ease of movement while performing an activity; and also no limitation in the transmitter to receiver orientation. In addition, the previous documented work on wearable antennas in the literature are mostly linear polarized [17, 18], large in size [19], non-flexible [20] and using thick substrate [21], which limit their employment in wearable applications.

In order to make the wearable antenna circularly polarized, modification in the radiating elements is required, such as truncated, feed arrangements, phase shifting, and slotted. On the other hand, some of the techniques that used to obtain $\mathrm{CP}$ wearable antenna are complex or can only achieve $\mathrm{CP}$ at very limited bandwidth without covering the desired band [1].

Therefore, in this paper, a fabric antenna designs by introducing the rectangular slot and the truncated edge of the patch in order to reduce the size and obtains CP. The truncated is chosen to avoid the complexity where the complexity is not preferred in fabric design in order to reduce the errors during fabrication. The useful of using wearable CP antenna is to optimize the off-body communication link when the antenna operates on moving person. The circularly polarized fabric antenna is studied and its performance in free space and on the body will be investigated. The proposed antenna covers the $2.4 \mathrm{GHz}$ ISM band. Furthermore, in order to protect the body from the influence of radio waves, the specific absorption rate (SAR) should be kept low enough.

\section{ANTENNA DESIGN}

The presented antenna is consisting of a dielectric which is sandwiched by a radiating element at the top layer and a full ground layer at the bottom. The full ground is used to act as shielding and reduce the user's impact on the fabric antenna performance when placed on the human body. The felt materials are used as the supporting materials due to its features that has a firm, inelastic and smooth surface, common fabric material used in daily clothing and has suitable dielectric constant and thickness. For the case of radiating element, Shieldit super with a thickness of $0.17 \mathrm{~mm}$ was selected due to a hot melt adhesive on one side that let it stick firmly with the fabric material. In this paper, the felt has a thickness of $2 \mathrm{~mm}$, relative permittivity of 1.3 and tangent loss of 0.02 .

\section{PERFORMANCE OF THE ANTENNA IN FREE SPACE}

Figure 1 illustrates the design of the presented fabric antenna with circular polarization. The initial stage of the design is started based on calculation. Based on the formula in [22], the overall dimension of the antenna is $66 \times 60 \times 2 \mathrm{~mm}^{3}$. Then, the design was optimized to resonate at the desired frequency of $2.4 \mathrm{GHz}$ with an overall dimension of $60 \times 60 \times 2 \mathrm{~mm}^{3}$. The detailed dimensions of the geometry is tabulated in Table 1 .

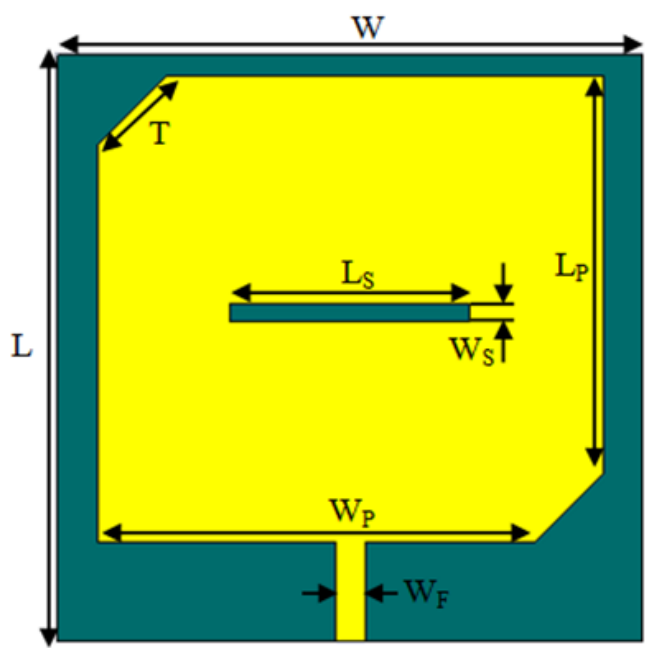

(a)

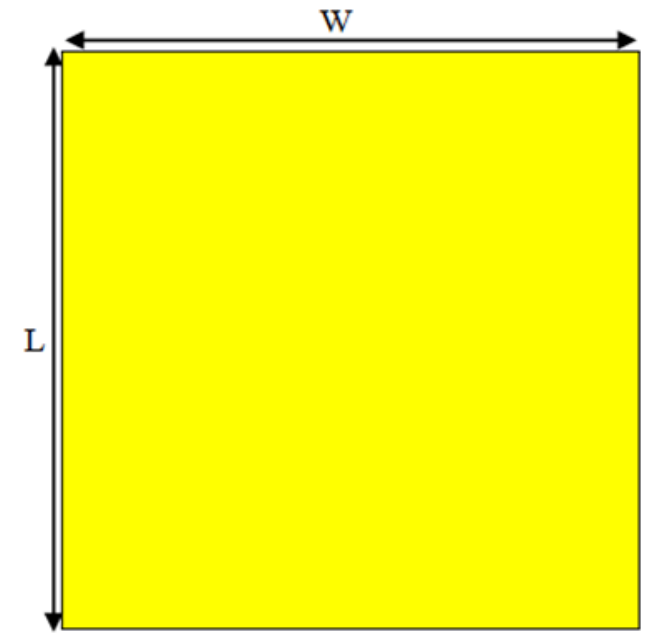

(b)

Figure 1. Circularly polarized fabric antenna (a) front view and (b) back view 
Table 1. Parameters of the Presented Fabric Antenna as Labeled in Figure 1

\begin{tabular}{cc}
\hline Parameters & Values [mm] \\
\hline W & 60 \\
L & 60 \\
WP & 44.8 \\
LP & 40.8 \\
WS & 1.8 \\
Ls & 24.6 \\
WF & 3 \\
T & 7 \\
\hline
\end{tabular}

The presented fabric antenna is analyzed using CST software. Figure 2(a) illustrates the reflection coefficient, $\mathrm{S}_{11}$ of the introduced design without slot and truncated corners. It is realized that the resonant frequency resonating at higher band. With the existence of a rectangular slot, the size of the presented wearable antenna is reduced and the resonant frequency is shifted to the lower band as seen in Figure 2(a). This is due to the effect of slots on changing the current path and increases the effective current path length. To achieve CP a truncated corner with equal side length is introduced. The truncation is optimized until the fabric antenna achieves $\mathrm{CP}$. In order to verify the $\mathrm{CP}$ of the antenna, the antenna must have an axial ratio (AR) bandwidth of less than $3 \mathrm{~dB}$. Figure 2(b) shows the AR result of the fabric antenna at different truncated values. The results indicate that when the truncated corners are $7 \mathrm{~mm}$, an acceptable AR below 3 $\mathrm{dB}$ is obtained, therefore attain circular polarization with $0.96 \mathrm{~dB}$ at desired frequency $2.4 \mathrm{GHz}$.

Figure 3 (a) shows the radiation pattern at E-plane and $\mathrm{H}$ - plane. It can see that the backward radiation is low which quite important since the antenna designed for the purpose of wearable. The low backward radiation is due to the full ground that contributes to reducing the radiation towards the body. Furthermore, the presented antenna has achieved a FBR of $10.5 \mathrm{~dB}$ and realized a gain of $4.62 \mathrm{~dB}$, respectively as presented in Figure 3 (b).

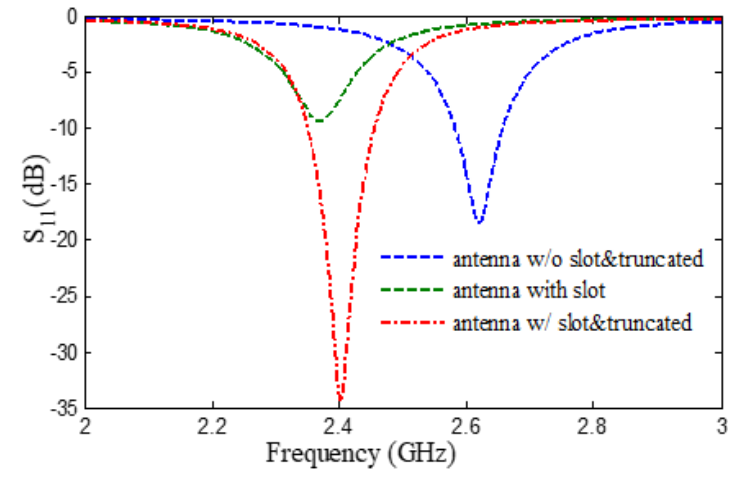

(a)

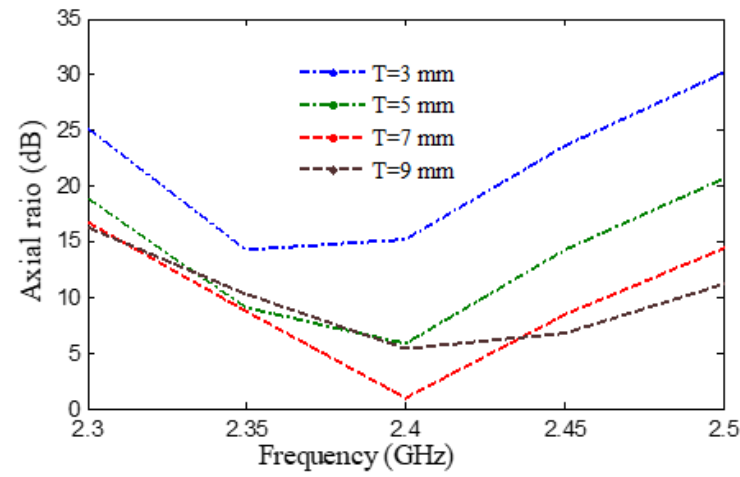

(b)

Figure 2. (a) $\mathrm{S}_{11}$ of the circularly polarized fabric antenna and (b) Axial radio with different truncated corners

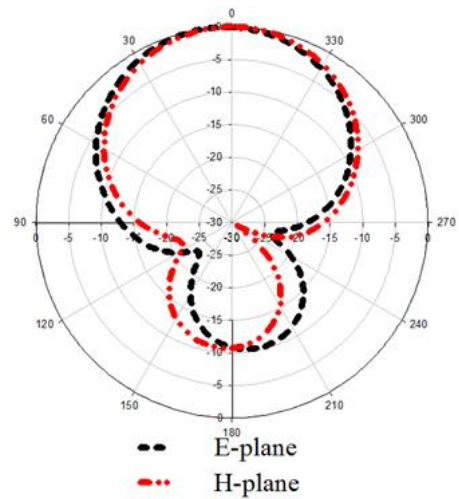

(a)

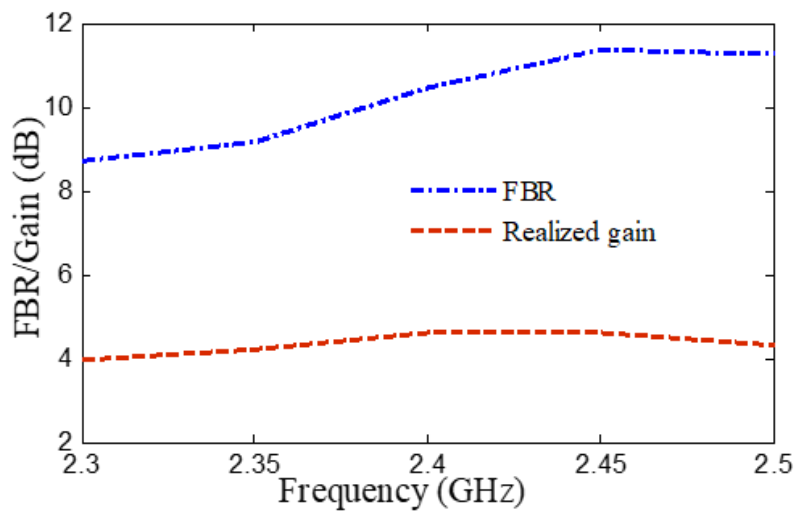

(b)

Figure 3. (a) Radiation pattern and (b) Gain and front to back ratio (FBR) 


\section{PERFORMANCE OF THE ANTENNA ON BODY}

Since this antenna is intended for wearable application, the antenna performance should be evaluated when operating in the proximity of the human body. In order to perform the analysis, a phantom model consists of four layers is designed to imitate the human chest. The layers consist of bone, skin, muscle and fat. The area size of the phantom is $150 \mathrm{~mm} \times 150 \mathrm{~mm} \times 40 \mathrm{~mm}^{3}$ [23-26]. Each layer has a its own thickness, mass density, permittivity and conductivity values as tabulated in Table 2 [24, 25]. The presented antenna was investigated at varies distances to the phantom by $0 \mathrm{~mm}, 2 \mathrm{~mm}, 5 \mathrm{~mm}$ and $8 \mathrm{~mm}$. The configuration of placement of the antenna on the phantom is illustrated in Figure 4.

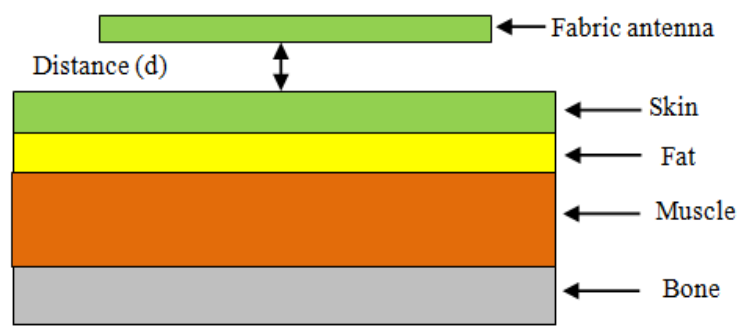

Table 2. Data of the Phantom [24, 25]

\begin{tabular}{lcccc}
\hline & Skin & Muscle & Fat & Bone \\
\hline Density $(\mathrm{kg} / \mathrm{m} 3)$ & 1001 & 1006 & 900 & 1008 \\
$\varepsilon$ & 37.95 & 52.67 & 5.27 & 18.49 \\
Thickness $(\mathrm{mm})$ & 2 & 20 & 5 & 13 \\
$\sigma_{(\mathrm{S} / \mathrm{m})}$ & 1.49 & 1.77 & 0.11 & 0.82 \\
\hline
\end{tabular}

Figure 4. A configuration of the fabric antenna on the phantom model

Based on Figure 5(a), the $S_{11}$ of the design is stable even when the antenna placed directly on the phantom. This is due to the presence of the full ground plane which reduced the impacts between the antenna and the human body. The <-10-dB return loss bandwidth is nearly the same as in free space. Figure 5(b) depicts the AR of the antenna with different distances between the antenna and the phantom. It also can be seen that the AR maintains stable as in the case of free space with a value of less than $3 \mathrm{~dB}$. The $\mathrm{AR}$ is range from $0.43 \mathrm{~dB}$ to $0.92 \mathrm{~dB}$. Based on AR results, the problem of restricted movements of the users while wearing the wearable device on their clothes is solved due to its independence of orientation.

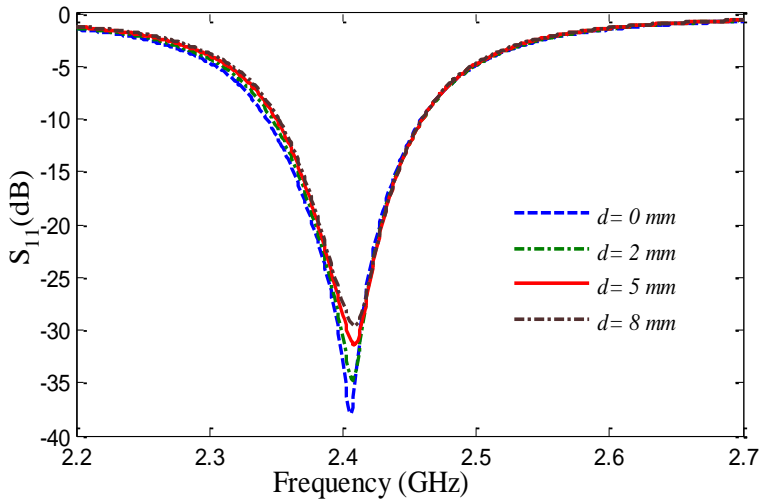

(a)

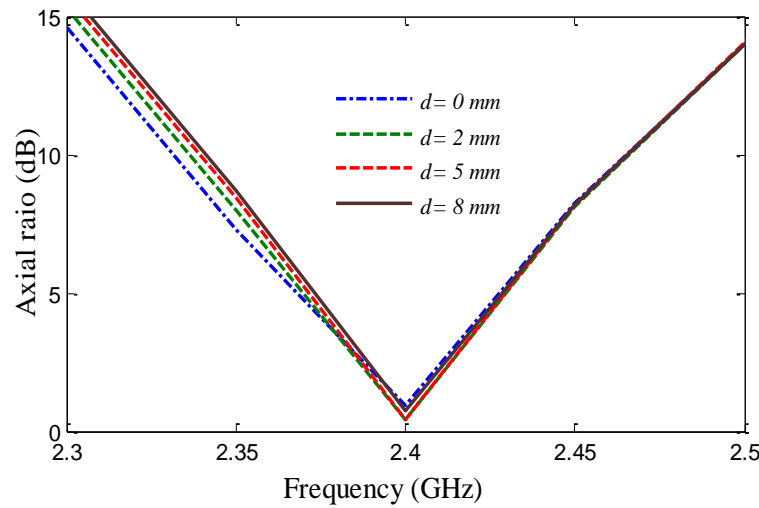

(b)

Figure 5. Antenna performances (a) with different distances between the phantom and the fabric antenna and (b) Axial with different distances between the phantom and the fabric antenna

Figure 6 shows the investigation of the radiation patterns with the same distances as studied in $\mathrm{S}_{11}$ and AR. In overall, radiation patterns with human proximity maintain close to that in free space. The front to back ratio is slightly increased which result in increasing the directivity. As a result, the increment of directivity also results in an increment on the gain range from $4.53 \mathrm{~dB}$ to $4.82 \mathrm{~dB}$ compared to free space as depicted in Figure 7. This is due to the human body which can behave as an extension of the ground plane [20]. 


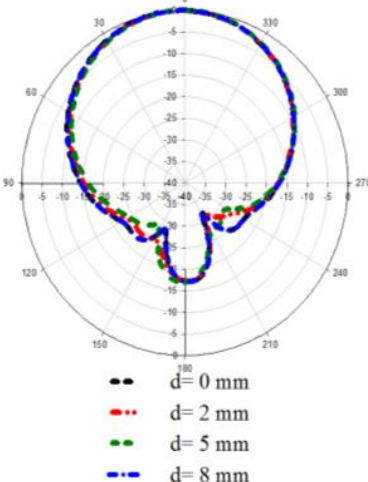

(a)

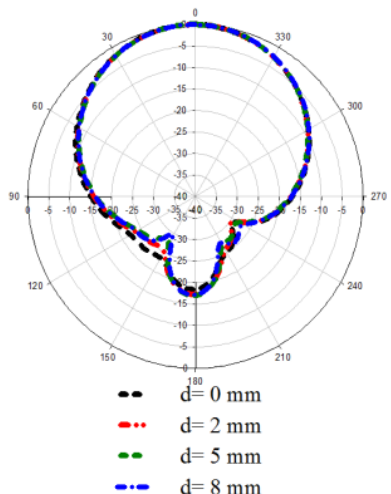

(b)

Figure 6. Radiation pattern with different distances between the phantom and the fabric antenna (a) E-plane and (b) H-Plane

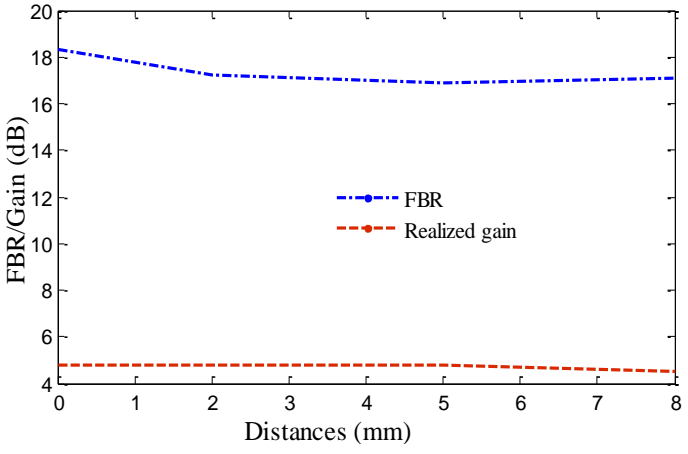

Figure 7. Realized gain and FBR with respect distances between the phantom and the fabric antenna

\section{SPECIFIC ABSORPTION RATE}

SAR is an essential feature of a fabric antenna in order to find the impacts of the electromagnetic waves on the human tissues. The safety limits of the SAR based on FCC is $1.6 \mathrm{~W} / \mathrm{Kg}$ over $1 \mathrm{~g}$ tissue. The same phantom model used to investigate the $S_{11}$ and AR is used for SAR analysis with the same distances. The input power set at $100 \mathrm{~mW}$ [24-27] and the evaluation of the values are according to IEEE C95.1 standard that obtainable in the CST MWS software. The results are depicted in Figure 8 and summarize in Table 3. It is realized that the antenna has values less than the safety level even when it places immediately on the phantom model.

Table 3. Saummary of SAR Values at Varies Distances

\begin{tabular}{cc}
\hline Spacing between the antenna and the phantom $(\mathrm{mm})$ & SAR over $1 \mathrm{~g}(\mathrm{w} / \mathrm{kg})$ \\
\hline 0 & 1.11 \\
2 & 0.23 \\
5 & 0.166 \\
8 & 0.12 \\
\hline
\end{tabular}

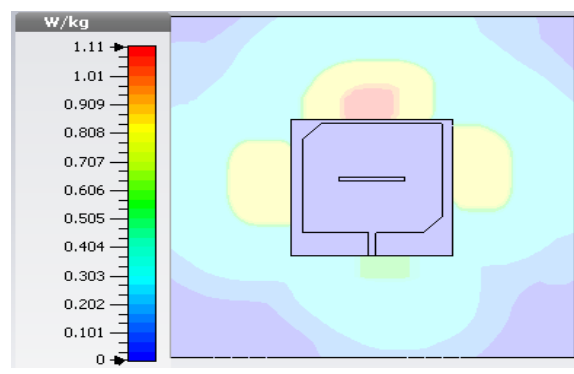

(a)

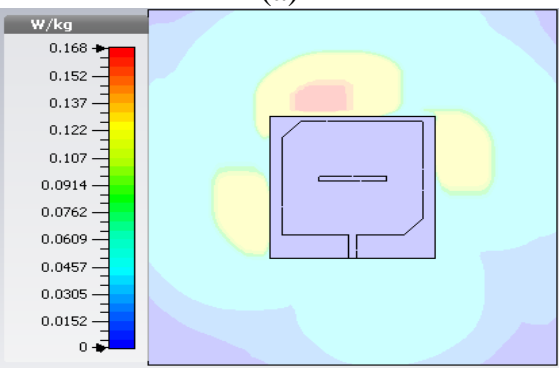

(c)

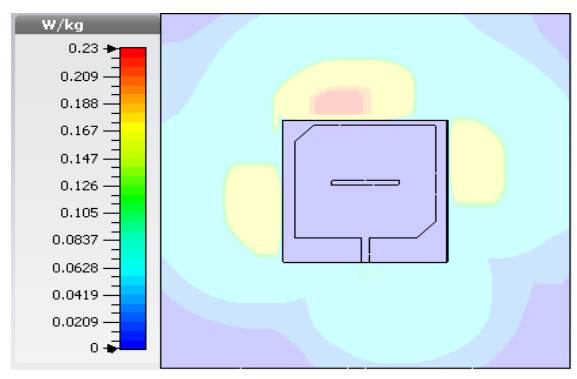

(b)

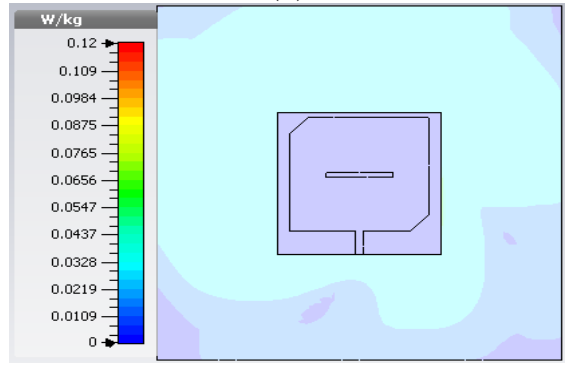

(d)

Figure 8. SAR investigation based on $1 \mathrm{~g}$ averaged with different distances from the phantom (a) at $0 \mathrm{~mm}$, (b) at $2 \mathrm{~mm}$, (c) at $5 \mathrm{~mm}$ and (d) at $8 \mathrm{~mm}$ 


\section{CONCLUSION}

This paper presented a compact and simple structure that operates at $2.4 \mathrm{GHz}$. The introduced slots and truncated corners in the design contribute to reduce the size and achieve the circular polarization. The fabric material is used to maintain flexibility and make it easily worn on the human body. The AR, FBR and realized the gain of the antenna in free space are $0.96 \mathrm{~dB}, 10.5 \mathrm{~dB}$, and $4.62 \mathrm{~dB}$, respectively. The presented antenna has been investigated when operating close to the human body with different distances in term of $S_{11}$, AR, FBR and realized the gain. The results showed that the design achieved good performance when operating near the body. Furthermore, SAR was studied and shows that the level complied with the basic restrictions for the general public. The results illustrated that the presented fabric antenna has suitable performance, even when it placed directly on the body. Therefore, we conclude that this presented fabric antenna is appropriate for wearable applications.

\section{ACKNOWLEDGEMENT}

The authors of this paper wish to acknowledge the funding of this project by Universiti Tun Hussein Onn Malaysia (UTHM) under TIER 1 Grant Vot No. H247.

\section{REFERENCES}

[1] K. W. Lui, O. H. Murphy, and C. Toumazou, "A Wearable Wideband Circularly Polarized Textile Antenna for Effective Power Transmission on a Wirelessly-Powered Sensor Platform," IEEE Trans. Antennas Propag., vol. 61, no. 7, pp. 3873-3876, Jul. 2013.

[2] A. Y. I. Ashyap, Z. Z. Abidin, S. H. Dahlan, H. A. Majid, S.Shah, M. R. Kamarudin and A.Alomainy, "Compact and Low-profile Textile EBG-based Antenna for Wearable Medical Applications," IEEE Antennas Wirel. Propag. Lett., vol. 1225, no. c, pp. 1-1, 2017.

[3] N. H. Sulaiman, N. A. Samsuri, M. K. A. Rahim, F. C. Seman, and M. Inam, "Compact Meander Line Telemetry Antenna for Implantable Pacemaker Applications," Indones. J. Electr. Eng. Comput. Sci., vol. 10, no. 3, p. 883, Jun. 2018.

[4] N. Othman, N. A. Samsuri, M. K. A. Rahim, K. Kamardin, and H. A. Majid, "Meander bowtie Antenna for Wearable Application," TELKOMNIKA (Telecommunication Comput. Electron. Control)., vol. 16, no. 4, p. 1522, Aug. 2018.

[5] A. Y. I. Ashyap, Z. Z. Abidin, S. H. Dahlan, H. A. Majid, M. R. Kamarudin, and R. A. Abd-Alhameed, "Robust low-profile electromagnetic band-gap-based on textile wearable antennas for medical application," in 2017 International Workshop on Antenna Technology: Small Antennas, Innovative Structures, and Applications (iWAT), 2017, pp. 158-161.

[6] F. C. Seman, F. Ramadhan, N. S. Ishak, R. Yuwono, Z. Z. Abidin, S. H. Dahlan, S. M. Shah, and A. Y. I. Ashyap, "Performance Evaluation of a Star-Shaped Patch Antenna on Polyimide Film Under Various Bending Conditions," Progress In Electromagnetics Research Letters, Vol. 85, 125-130, 2019.

[7] E. K. Kaivanto, M. Berg, E. Salonen, and P. de Maagt, "Wearable Circularly Polarized Antenna for Personal Satellite Communication and Navigation," IEEE Trans. Antennas Propag.,59(12), pp. 4490-4496, Dec. 2011.

[8] A. Y. I. Ashyap, W. N. N. W. Marzudi, Z. Z. Abidin, S. H. Dahlan, H. A. Majid, and M. R. Kamaruddin, "Antenna incorporated with Electromagnetic Bandgap (EBG) for wearable application at $2.4 \mathrm{GHz}$ wireless bands, ” ReIEEE Asia-Pacific Conference on Applied Electromagnetics (APACE), 2016, no. December, pp. 217-221.

[9] A. Y. I. Ashyap, Z. Z. Abidin, S. H. Dahlan, H. A. Majid, and F. C. Seman, "A Compact Wearable Antenna Using EBG for Smart-watch Applications,” 2018 Asia-Pacific Microw. Conf., pp. 1477-1479, 2018.

[10] M. A. Abdullah, M. K. A Rahim, N. A. Samsuri, and K. Kamardin, "On-Body Transmission Single-Band Diamond Dipole Antenna with Waveguide Jacket," Indones. J. Electr. Eng. Comput. Sci., vol. 10, no. 3, p. 1212, Jun. 2018.

[11] A. N. Suraya et al., "Wearable antenna gain enhancement using reactive impedance substrate," Indones. J. Electr. Eng. Comput. Sci., vol. 13, no. 2, p. 708, Feb. 2019.

[12] A. Y. I. Ashyap, Z. Z. Abidin, S. H. Dahlan, H. A. Majid, Z. Muhammad, M. R. Kamarudin," Parametric Analysis of Wearable Vialess EBG Structures and Its Application for Low Profile Antennas ," TELKOMNIKA (Telecommunication Comput. Electron. Contro)l., Vol 15, no. 2, p. 718-725, June 2017.

[13] S. Shawalil, K. Najmy, A. Rani, and H. A. Rahim, "2.45 GHz wearable rectenna array design for microwave energy harvesting,” Indones. J. Electr. Eng. Comput. Sci., vol. 14, no. 2, pp. 677-687, 2019.

[14] Saleh G, Solbach K, Erni D, Ashyap A. Tuning high impedance surfaces using coaxial cables for magnetic resonance imaging machines. Int J RF Microw Comput Aided Eng. 2018; 28:e21477.

[15] M. Rizwan, L. Sydänheimo, and L. Ukkonen, "Impact of bending on the performance of circularly polarized wearable antenna,” Prog. Electromagn. Res. Symp., vol. 2015-Janua, no. 2015, pp. 732-737, 2015.

[16] M. H. Chowdhury, Q. D. Hossain, A. Hossain, R. Chak, and C. Cheung, "Single feed circularly polarized crescentcut and extended corner square microstrip antennas for wireless biotelemetry," International Journal of Electrical and Computer Engineering (IJECE)., vol. 9, no. 3, pp. 1902-1909, 2019. 
[17] A. Y. I. Ashyap, Z. Z. Abidin, S. H. Dahlan, H. A. Majid, Waddah. A. M. A, M. R. Kamarudin, George Adeyinka Oguntala, Raed A. Abd-Alhameed, James M Noras, "Inverted E-Shaped Wearable Textile Antenna for Medical Applications," IEEE Access, vol. PP, no. c, pp. 1-1, 2018.

[18] Z. Muhammad, S. M. Shah, Z. Z. Abidin, A. Y. I. Asyhap, S. M. Mustam, and Y. Ma, "CPW-fed wearable antenna at 2.4 GHz ISM band," AIP Conference Proceedings 2017, vol. 20003, p. 20003.

[19] A. Y. I. Ashap, Z Z Abidin, S H Dahlan, H A Majid, S K Yee, Gameel Saleh, and Norun Abdul Malek, "Flexible Wearable Antenna on Electromagnetic Band Gap using PDMS substrate," TELKOMNIKA (Telecommunication Comput. Electron. Control), vol. 15, no. 3, pp. 9-12, 2017.

[20] M. A. B. Abbasi, S. S. Nikolaou, M. A. Antoniades, M. Nikolić Stevanović and P. Vryonides, "Compact EBGbacked planar monopole for BAN wearable applications," IEEE Trans. Antennas Propag.,vol. 65, no. 2, pp. 453463, Feb. 2017.

[21] Alqadami, A. S. M. and M. F. Jamlos, "Design and development of a fexible and flelastic UWB wearable antenna on PDMS substrate," IEEE Asia-Pacific Conference on Applied Electromagnetics (APACE), 27-30, Dec. 2014.

[22] N.Mohamed Sabidha Banu, Dr.M. Ramkumar Prabhu, U.T. Sasikala, "Design A Square Microstrip Patch Antenna for S-Band Application", IOSR Journal of Electronics and Communication Engineering (IOSR-JECE), e-ISSN: 2278- 2834,p- ISSN: 2278-8735.Volume 10, Issue 2, Ver. ,PP 24- 30, Mar - Apr.2015.

[23] Z. H. Jiang and D. H. Werner, "Robust low-profile metasurface-enabled wearable antennas for off-body communications," in 8th European Conference on Antennas and Propagation, EuCAP 2014, 2014, vol. 3003, no. EuCAP, pp. 21-24.

[24] A. Y. I. Ashyap, Z. Z. Abidin, S. H. Dahlan, H. A. Majid, M. R. Kamarudin, "Highly Efficient Wearable CPW Antenna Enabled by EBG-FSS Structure for Medical Body Area Network Applications," IEEE Access, vol. 6, pp. 77529-77541, 2018.

[25] Z. H. Jiang, D. E. Brocker, P. E. Sieber, and D. H. Werner, “A Compact, Low-Profile Metasurface-Enabled Antenna for Wearable Medical Body-Area Network Devices,” IEEE Trans. Antennas Propag., vol. 62, no. 8, pp. 4021-4030, Aug. 2014.

[26] A. Y. I. Ashyap, Zainal Abidin Z, Dahlan SH, Majid HA, Saleh G. Metamaterial inspired fabric antenna for wearable applications. Int J RF Microw Comput Aided Eng. 2018; e21640.

[27] Y.-S. Chen and T.-Y. Ku, "A Low-Profile Wearable Antenna Using a Miniature High Impedance Surface for Smartwatch Applications," IEEE Antennas Wirel. Propag. Lett., vol. 15, no. c, pp. 1144-1147, 2016.

\section{BIOGRAPHIES OF AUTHORS}

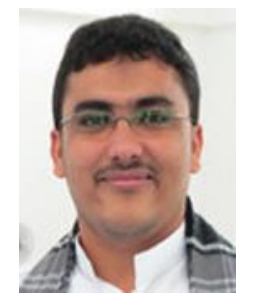

Adel Ashyap received the B.Eng., M.Eng and Ph.D. Degree in electrical engineering from Universiti Tun Hussein Onn Malaysia (UTHM), in 2012, 2014, 2019, respectively. He is currently a Postdoctoral Fellow with the Research Center of Applied Electromagnetics, Faculty of Electrical and Electronic Engineering, Universiti Tun Hussein Onn Malaysia (UTHM), Johor, Malaysia. He has authored or co-authored numbers of journals and proceedings. His research interests include electromagnetic bandgap (EBG), artificial magnetic conductor (AMC) for wireless body area networks (WBAN), microstrip antennas and small antennas for biomedical devices. He was received Chancellor Award for his final year project and a number of Gold, Silver and Bronze medals in international and local competitions.

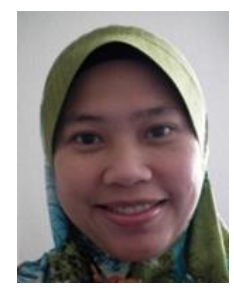

Zuhairiah Zainal Abidin received her B.Eng.from the Universiti Teknologi Malaysia, in 2001, the M. Eng from the Kolej Universiti Tun Hussein Onn Malaysia, Johor, Malaysia, in 2003, and Ph.D. degree from Bradford University, U.K in 2011. Currently, she was a Principal Researcher at Applied Electromagnetic Center, Universiti Tun Hussein Onn Malaysia. She has authored and coauthored numbers of journals and proceedings, including the IEEE TRANSACTION ON ANTENNA AND PROPAGATION and IEEE AWPL. Her research interests include MIMO antenna, printed microstrip antenna, wearable antennas, electromagnetic bandgap (EBG) for wireless and mobile and high speed digital circuit's applications.

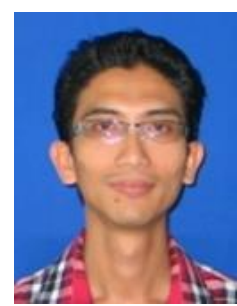

Samsul Haimi Dahlan received his PhD degree in Signal Processing and Telecommunications from the Universite de Rennes 1, France, in 2012. He is a Senior Lecturer with the Faculty of Electric and Electronic Engineering, Universiti Tun Hussein Onn Malaysia (UTHM) since March 2012. Currently he is with the Research Center for Applied Electromagnetics (EMCenter, UTHM) as the principal researcher and appointed as the Head of the center since April 2015. He has authored and co-authored numbers of journals including the IEEE TRANSACTION on ELECTROMAGNETIC COMPATIBILITY and IEEE AWPL. His research interest includes Optical-Microwave generator, focusing system (dielectric lens and transmitarray's synthesis), computational electromagnetic technique namely the BOR-FDTD and material characterizations. He is supervising a numbers of $\mathrm{Ph} . \mathrm{D}$, master's, and bachelor's students and involved in several research projects sponsored by the industry and government agencies. 

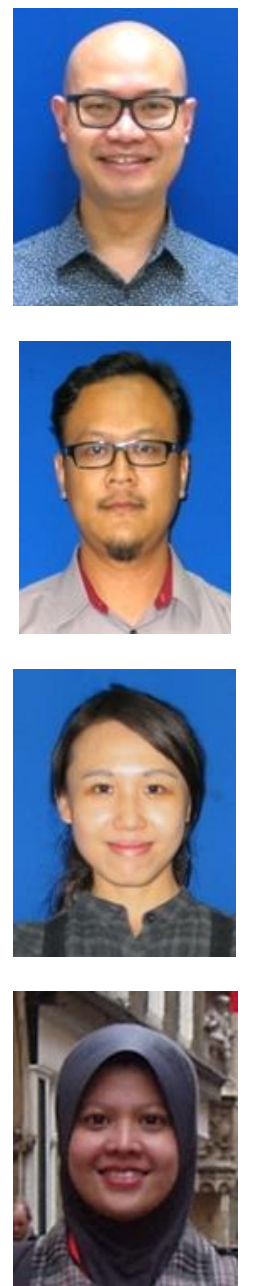

Shaharil Mohd Shah obtained his B. Eng in Microwave and Communication from Multimedia University (MMU) in 2002. He received his M.Sc in Microwave Engineering and Wireless Subsystems Design from the University of Surrey, UK in 2004 and pursuing his Ph.D in Communication Engineering from the University of Birmingham, UK before graduating in 2016. $\mathrm{He}$ is currently a senior lecturer in the Department of Communication Engineering, Faculty of Electrical and Electronic Engineering, Universiti Tun Hussein Onn Malaysia (UTHM). His area of research includes, but not limited to, design of microwave devices, active antennas measurement and nonlinear characterisation of active devices.

Huda A Majid received the B Eng. degree in Electrical Engineering (Telecommunication) from Universiti Teknologi Malaysia, in 2007. He then obtained his M.Eng in 2010 and PhD degrees in Electrical Engineering in 2013, at Universiti Teknologi Malaysia. He is currently a lecturer in the Department of Electrical Engineering Technology, Faculty of Engineering Technology, Universiti Tun Hussein Onn Malaysia. His research interest includes the areas of design of microstrip antennas, small antennas, Reconfigurable antennas, metamaterials structure, metalaterial antennas and millimeter wave antennas. He has published over 50 articles in journals and conference papers.

S.K. Yee is a principal researcher in Research Center for Applied Electromagnetic and lecturer in the Department of Communication Engineering, Faculty of Electrical and Electronic Engineering, Universiti Tun Hussein Onn Malaysia (UTHM). She received his PhD from the Faculty of Electrical and Electronic Engineering, Universiti Tun Hussein Onn Malaysia (UTHM) in 2015. Her research interests include shielding effectiveness, dielectric measurement techniques and its application in sensing.

Norun Abdul Malek has been appointed as an assistant lecturer in 2006 and currently serves as Assistant Professor in the Department of Electrical and Computer Engineering, Faculty of Engineering, International Islamic University Malaysia (IIUM). Norun lectures on subjects in Antennas and Wave Propagation, Fundamental of Communication Engineering, Digital Signal Processing, Signals and Systems, RF design, Antenna and Propagation for undergraduate and postgraduate levels, at the Department of Electrical and Computer Engineering. Her research concentrations are in the area of Numerical analysis especially in antenna arrays, signal processing and optimization techniques. Her research area also does not limit to wearable antennas and antennas using metamaterials for wireless communications. Norun received a MSc. degree in Digital Communication Systems from the Loughborough University, UK and a Ph.D. degree in Electrical and Electronic Engineering from the same university in 2008 in 2013, respectively. She is also a member of the IEEE and IEM, and registered under the Board of Engineering Malaysia. 